\title{
Six-pack balancing act: A conceptual model for the intestinal lining
}

PK RANGACHARI, MBBS, PHD

ABSTRACT: The cells that form the lining of the intestine belong to a class of cells termed 'polarized' or 'asymmetric.' The membranes surrounding these cells show functional differences at the luminal and contraluminal surfaces. The cells line up to form sheets and it is across these sheets that movement of fluids and solutes occurs. Such movement occurs in both directions across the lining and the occurrence of diarrhea or constipation depends to a considerable extent upon the net result of the absorptive and secretory mechanisms and their modulation by a host of factors such as neurotransmitters, bacterial products, drugs, etc. This review provides a simple framework for understanding the dynamics of the gut lining. Diamond's six-pack model of epithelia is modified to include the dynamic tension between absorptive and secretory mechanisms. Can J Gastroenterol 1990;4(5):201-208

Key Words: Gut function, Review, Transport

\section{La dynamique du porte-bières: Modèle conceptuel de la muqueuse de l'intestin}

RESUME: Les cellules constituant la muqueuse de l'intestin font partie de la classe de cellules dites polarisées ou asymétriques. Les membranes qui enveloppent ces cellules assument différentes fonctions selon qu'elles appartiennent à la surface luminale ou basale. Les cellules s'alignent pour former des couches à travers lesquelles s'opère l'échange des liquides et solutés. De tels mouvements s'effectuent dans les deux sens à travers la muqueuse, et la survenue de la diarrhée ou de la constipation dépend dans une large mesure du résultat net des mécanismes absorbants et sécrétoires, et de leurs modulations conditionnées par une foule de facteurs tels les neurotransmetteurs, les produits bactériens, les médicaments, etc. Cette étude offre un cadre de travail simple permettant de saisir la dynamique de la muqueuse intestinale. Le modèle épithélial du portebières élaboré par Diamond est modifié pour inclure la tension dynamique existant entre les mécanismes absorbants et sécrétoires.
$\mathrm{T}$ HE SHEET OF CELLS THAT LINES the intestinal tract stands at the interface of two worlds - the outside world of the gut lumen and the inside world of the body. Materials that are ingested remain external until they traverse this sheet, enter the bloodstream and are incorporated into the form and substance of the body. This lining which plays a crucial role in the body's economy is subjected to a barrage of influences from both luminal and contraluminal aspects. It is the objective of this review to provide a conceptual framework for understanding the functions of this lining and the influences that impinge on it. No attempt will be made to discuss these factors exhaustively, and the reader is referred to several recent reviews for details $(1-8)$.

The clinician is faced with the task of understanding the functions of this lining when he or she is confronted with a patient suffering from diarrhea. Although a precise and universally acceptable definition of diarrhea may be difficult, a functional definition can be given. Thus, Turnberg (9) commented that from a functional point of view, diarrhea can be defined as a "malabsorption of water." The task of the basic scientist lies in understanding the mechanisms responsible for this malabsorption and communicating that in- 


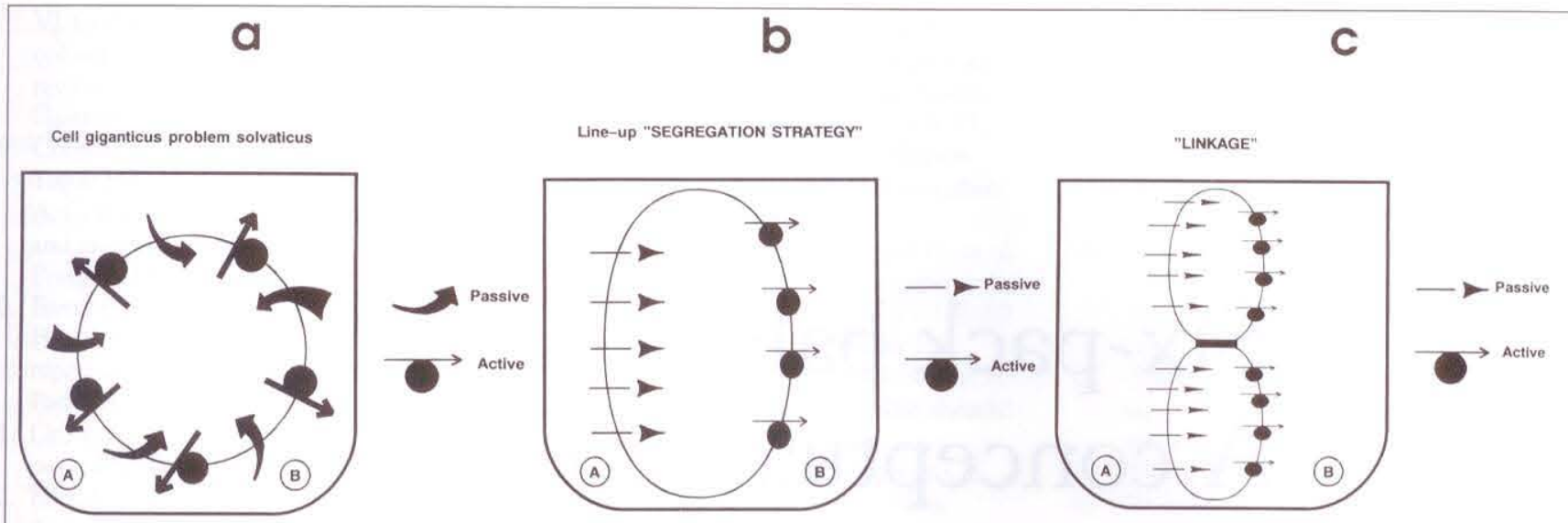

Figure 1) A 'thought experiment' to demonstrate the differences between symmetrical and polarized cells. a An imaginary cell (cell giganticus problem solvaticus) is dropped into a beaker of isotonic sodium chloride and asked to transport sodium ions so as to reduce the concentration of sodium ions on side A and increase it on side B. The cell, being symmetrical, has a fairly uniform distribution of entry and exit steps; it is assumed that the entry steps are passive and the exit steps are active (solid circles represent active exit steps). Such an organization prevents the cell from transporting sodium ions across the cell. b Here the cell has attempted to solve the problem by a segregation strategy. The entry and exit steps are separated as shown. Now, sodium ions entering the cell from side A are pumped out into the solution facing side B. This maneuvre is not entirely successful, since the sodium ions pumped out on side B quickly diffuse through the bathing medium to side A, $\mathrm{c}$ Here two cells have linked up in such a way that the entry and exit steps are separated. Back-diffusion of sodium ions is restricted by the 'seals' between the cells. If a large number of cells join together, an epithelial sheet is formed. Sodium ions can be transferred across the entire sheet. The symmetrical cells are now polarized with the properties of the membrane on one side being different from those on the other

formation to the busy clinician. That this is not a trivial task is emphasized by a recent editorial comment by Snyder (10) entitled 'Too many deaths from diarrhea.' The comment was provoked by a study that showed that during the years 1973 to 1983 , there were 500 deaths per year due to diarrhea in the United States. It was disturbing that not only did these deaths occur in an advanced industrialized nation rather than in the Third World, but 50\% of the deaths occurred after the child had reached a medical facility (11).

\section{TRANSPORT ACROSS SYMMETRICAL AND POLARIZED CELLS: \\ A THOUGHT EXPERIMENT}

To understand the mechanisms responsible for the malabsorption of water, it is important to define the processes by which water moves across the intestinal lining. To begin we can make the dogmatic assertion that in biological systems the movement of solutes is primary with the movement of water being secondary. Or to put it simply water follows salt. The problem thus resolves itself into understanding the mechanisms by which solute movement occurs across the intestine.

Transport physiologists divide cells into two broad categories-symmetrical and polarized. The classical example of a symmetrical cell would be the erythrocyte, the smooth muscle cell or the nerve cell. The enterocyte, the parietal cell, the cell lining the renal tubule and those lining the airways are good examples of polarized cells. To understand the distinctions between the two classes, it would be instructive to begin with a simple 'thought experiment.'

Imagine that a gigantic erythrocyte or its equivalent is dropped into a beaker containing isotonic sodium chloride and asked to pump sodium ions from side A to side B (Figure 1a). Since this is a thought experiment, we can endow the cell with the capacity to solve problems and call it 'cell giganticus problem solvaticus.' Symmetrical cells are characterized by a fairly uniform distribution of transporters. Thus, the cell possesses entry and exit steps for sodium ions that are dis- tributed symmetrically as shown in Figure 1a. If the entry step is passive and the exit step active, the sodium ions entering the cell would be pumped out by an energy-consuming process. Given the distribution of entry and exit steps, the cell would be unable to achieve its goal of reducing the concentration of sodium ions on side $\mathrm{A}$ and increasing it on side B.

Since, however, the cell is capable of solving problems, it could attempt to reorganize the entry and exit steps in the fashion shown in Figure 1b. Here the cell has lined up all the entry steps on one side and all the exit steps on the other. Now, sodium ions enter from side $A$ and are pumped out from side $B$. The intentions of this 'segregation strategy' may be laudable but would fail in the long run. Simply put, the backflux of sodium ions from side $B$ to side $A$ in the bathing solution nullifies the effect.

However, a simple addition to the segregation design can solve the problem. If the sentient cell can find other likeminded cells, they can link up in such a way that entry and exit steps are separated, and the junctions between 
the cells can act to limit backflux (Figure 1c). In essence, this is the organization of the lining of the gut, the airways, the renal tubule, etc. Geometry, thus, plays a crucial role, and to understand the functioning of an epithelial cell, it is important to understand the spatial separation of transporting elements (ie, the properties of the apical and basolateral membranes) as well as the properties of the junctions.

\section{THE SIX-PACK MODEL OF EPITHELIAL ORGANIZATION}

A simple heuristic model for understanding epithelial organization was proposed by Diamond (12). The model has been modified and presented with suitable Canadian content in Figure 2. This model proposes that epithelial cells are basically organized as six-packs of beer extending in two dimensions. The beer cans correspond to the epithelial cells with the pop-top end of the beer cans corresponding to the apical cell membranes, the walls of the cans to the lateral cell membranes and the bottoms of the cans to the basal cell membranes. The spaces between the cells correspond to the lateral intercellular spaces and the plastic of the sixpack to the tight junctions that encircle the apical end of each cell and separate the luminal solution from the lateral intercellular spaces.

The analogy is not, however, exact, since there are gap junctions and desmosomes that serve to interconnect adjacent cells as well. Thus the six-pack, unlike the epithelial sheet, can be flexed. Given this organizational pattern, there are two possible routes for permeation across the epithelial sheet. These are termed 'transcellular' (through the cells) and 'paracellular' (between the cells).

The crucial role of geometry and sidedness in epithelial function cannot be overestimated. The mechanisms responsible for the maintenance of 'sidedness' have been studied using cultured epithelial cells (13). Cell-to-cell and cell-to-substratum contact appear to play a crucial role. When epithelial cells are isolated they appear to lose their polarity; this property is very quickly regained if the isolated cells

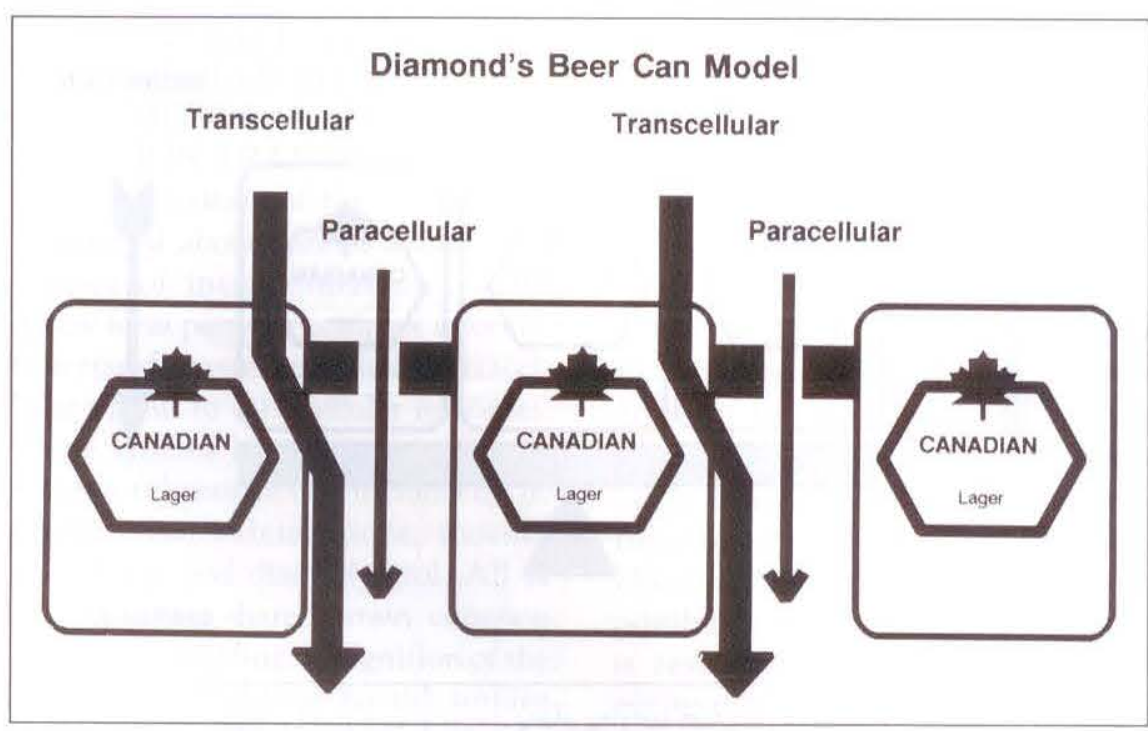

Figure 2) Diamond 'six-pack model' of epithelial organization. The beer cans form the epithelial cells with distinct apical and basolateral surfaces. The plastic of the six-pack models the tight junctions that surround each cell

make contact with a substratum. Such attachment is sufficient to induce a rapid polarization of apical membrane proteins to the free surface within 12 to $24 \mathrm{~h}$. These changes can be brought about by alterations in the cytos. keleton. Cell-to-cell contacts occur and result in the formation of tight junctions, and the apical and basolateral domains become demarcated. The differing protein compositions of the apical and basolateral surfaces are maintained by the coordinated insertion of new proteins and the degradation of old proteins. How this is done is not entirely clear; either the sorting of the proteins destined for the apical or basolateral surfaces occurs intracellularly, or the proteins are first inserted into the basolateral surface and the apical proteins removed and relocated to the apical surface. It is important to realize that the separation of these proteins is important for homeostasis. This 'sidedness' can be lost in several pathological conditions with serious consequences. In renal ischemia and polycystic kidney, there is a loss of sodium pump sites from the basolateral surface with their appearance on the apical surface. Defects in targeting appropriate proteins to the apical surface of the enterocyte may lead to congenital disorders such as microvillus inclusion disease.

\section{GENERAL ORGANIZATION OF INTESTINAL TRANSPORT: TERMS USED}

Across the intestinal epithelium, transport of ions and water occurs in both directions, ie, from lumen to blood and vice versa. Two terms are used to define these movements. Absorption refers to the movement of solute and water from lumen to blood, whereas secretion defines movement in the opposite direction. In the intestine, movement in either direction occurs along the entire length of the gut and "it is useful to think of the function of the mucosa as varying along a continuum from a maximal absorption to a maximal secretory state" (2). The final result is the algebraic sum of all of the absorption and secretion of fluid that occurs along the entire length of the gut (Figure 3 ).

In general, the intestine receives $9 \mathrm{~L}$ of fluid per day -1.5 to $2 \mathrm{~L}$ from ingested food and liquids and the rest from endogenous secretions (salivary, gastric, pancreatic, biliary and intestinal). Eighty-four per cent of the fluid is absorbed in the small bowel with the colon absorbing $11 \%$, leading to a net fecal output of 150 to $200 \mathrm{~mL}$ per day. This organizational pattern is very similar to that of the renal tubule where the proximal segments reabsorb the major portion of the solute and water 

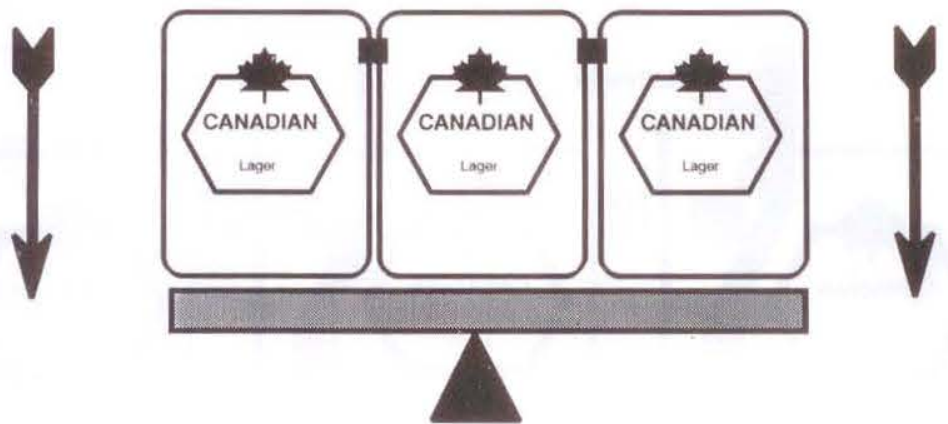

CONSTIPATION

DIARRHEA

Figure 3) Concept of intestinal function varying along a continuum from a maximal absorptive to a maximal secretory state. Here the six-pack has been placed on a fulcrum; tilting the balance to one side or the other can promote either diarrhea or constipation (cf reference 3)

\section{LUMEN}
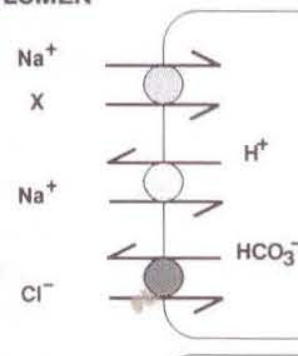

"villus Coll"
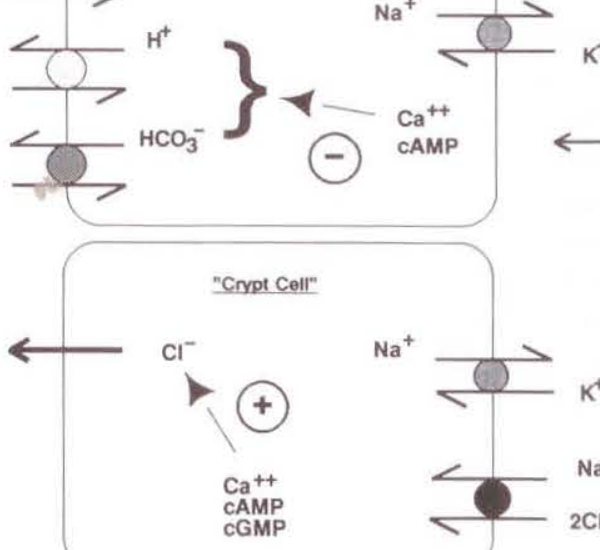

BLOOD

$\mathrm{Na}^{+}$

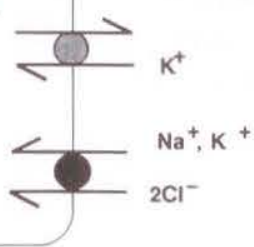

Figure 4) Villus-crypt model of intestinal function. For the sake of simplicity, only a few salient features have been shown. The $\mathrm{Na}^{+} / \mathrm{H}^{+}$antiport, the $\mathrm{Cl}^{-} / \mathrm{HCO}_{3}{ }^{+}$antiport and the $\mathrm{Na}^{+}$-organic substrate symports are shown in the apical surface of the villus cell. X refers to glucose, amino acids, etc. Each symport is a distinct molecular entity. Potassium ions enter the cell through the $\mathrm{Na}^{+} / \mathrm{K}^{+}$ pump and by the $\mathrm{Na}^{+} / \mathrm{K}^{+} / 2 \mathrm{Cl}$ symport. The potassium ions leak out through a pathway in the basolateral surface (not shown). The villus cell absorbs sodium and chloride ions, and the crypt cell secretes chloride ions into the lumen. The role of CAMP and calcium ions in the modulation of transport processes in these cells is noted in the text. (More complete diagrams that include other transporting elements are available in references $1,2,6$ and 7)

(obligatory reabsorption), leaving the rest to the distal segments (facultative reabsorption). The analogy to the renal tubule can be drawn even further, for in both the gut and the kidney the proximal segments are leakier, have transport processes for glucose and amino acids, and are insensitive to the mineralocorticoid aldosterone. The distal segments do not possess transport systems for glucose and amino acids and are sensitive to aldosterone, permitting fine tuning of water and electrolyte balance. If the solute load exceeds the reabsorptive capacities of the distal segments, diuresis or diarrhea results. The central role of the colon has been emphasized by describing diarrhea as "a failure of colonic lavage" (1).

\section{THE VILLUS-CRYPT MODEL}

Malabsorption of water can be due to net decreases in absorption, net increases in secretion, or a combination of both. Since net movement of water is secondary to movement of solute, much attention has been focused on defining the transporters involved. A current paradigm links absorptive processes to the villus cell and secretory processes to the crypt cell. A number of transporting elements have been identified (Figure 4). Several terms are commonly used to describe these transporters. Where a single solute traverses the membrane using a channel, the term 'uniport' is often used. The term 'antiport' or 'countertransport' refers to the movement of two ions or molecules in opposite directions, while 'symport' or 'cotransport' refers to the movement of two solutes in the same direction.

In both villus and crypt cells, a sodium pump $\left(\mathrm{Na}^{+}, \mathrm{K}^{+}\right.$-ATPase $)$located on the basolateral membrane creates an inwardly directed sodium ion gradient that provides a driving force for the entry of several ions. However, the energy provided by this gradient is harnessed to different ends in the two cells, dictated largely by the presence of specific transporters. In the villus cell, this inwardly directed sodium ion gradient allows sodium ions to enter by a variety of carrier-mediated processes ( $\mathrm{Na}^{+} /$glucose symport, $\mathrm{Na}^{+} /$amino acid symport, $\mathrm{Na}^{+} / \mathrm{H}^{+}$antiport, etc). The $\mathrm{Na}^{+} / \mathrm{H}^{+}$antiport allows the cell to extrude hydrogen ions produced within the cell in exchange for sodium ions. The operation of this transporter is closely linked to that of a $\mathrm{Cl}^{-} / \mathrm{HCO}_{3}{ }^{-}$ antiporter which allows chloride ions to enter in exchange for bicarbonate. The net result is sodium chloride reabsorption. Evidence that these transporters are unique comes from genetic defects. Congenital chloride diarrhea is a con- 
dition in which a genetic defect leads to the absence of a $\mathrm{Cl}^{-} / \mathrm{HCO}_{3}{ }^{-}$antiporter in the ileum. The patients suffer from watery diarrhea at birth which may manifest antenatally as hydramnios. Another genetic defect, more recently described, arises from the absence of the $\mathrm{Na}^{+} / \mathrm{H}^{+}$antiporter.

Chloride secretion by the crypt cell is also driven by the serosally located $\mathrm{Na}^{+}, \mathrm{K}^{+}$-ATPase, which in conjunction with a $\mathrm{Na}^{+} / \mathrm{K}^{+} / \mathrm{Cl}^{-}$symport allows chloride ions to enter the cell. The accumulated chloride ions can leave the cell across the apical membrane through specific channels with openings controlled by intracellular messengers such as CAMP or calcium ions. Transport processes for potassium ions exist as well. Colonic transport processes show regional variation but appear to be distinct from those in the small intestine. Thus sodium ion entry occurs in the distal colon via an electrogenic step that is inhibited by the diuretic amiloride and modulated by aldosterone. As mentioned above, this serves to strengthen the analogy of the renal tubule. Glucose and amino acid transporters do not exist.

The concept of crypt-villus separation of absorption and secretion has served as a good working model but may not represent the whole picture. Evidence in favour of such separation came from studies in which epithelia lacking villi such as the colon responded to stimulants with active anion secretion. Fluid droplets were observed over the crypt openings in the colon following stimulation. In epithelia that lacked crypts, such as the flounder intestine or the rabbit gallbladder, cAMP inhibited absorption but did not stimulate secretion. However, evidence exists which casts doubt on a simple, clear separation between villus and crypt. A recent microelectrode study of the rat small intestine suggested that the apical membranes of both villus and crypt cells responded to secretagogues, such responses requiring the presence of chloride ions in the fluid bathing the serosal (blood) side of the epithelium. This suggests that chloride ion secretion could occur in both cell types (14).

\section{INTRACELLULAR MEDIATORS AND MODULATION OF ION TRANSPORT}

The activities of the transporters mentioned above can be altered by a variety of intracellular mediators. These form part of a complex information transfer system that links extracellular signals to intracellular responses. These systems have as protagonists a variety of chemicals that includes cyclic nucleotides, calcium ions, inositol phosphates and diacylglycerol. All of these systems share certain common elements, including: recognition of the signal by membrane-bound surface receptors; coupling between the receptor and transducing elements; transduction of the message; transmission of the message by the chemical messengers; elicitation of the response; and termination of the message by the reduction of the signal (destruction of hormone, transmitter) or the messenger (destruction of cyclic nucleotides, sequestration of calcium ions). Particular attention has been paid to the modulation of sodium and chloride ion transport processes by cAMP and calcium ions.

Cyclic AMP: Cyclic AMP is an intracellular mediator that serves to link hormone receptor activation with physiological responses in a variety of cells. Occupation of membrane-bound receptors by hormones such as vasoactive intestinal peptide sets in motion a cascade of events. Playing a crucial role are a family of proteins termed ' $\mathrm{G}$ proteins' that act as signal transducers, coupling occupation of receptors to activation of adenylate cyclase, which acts as the effector (16). The G proteins have a trimeric structure and are composed of three subunits: $\alpha, \beta$ and $\gamma$. In its inactive form, the $\alpha$ subunit binds guanosine diphosphate (GDP). Occupation of the receptors serves not only to dissociate GDP from the $\alpha$ subunit, but permits binding of guanosine triphosphate (GTP). The $\alpha$ subunit then dissociates from the other two and the $\alpha$-GTP complex acts on its target, adenylate cyclase, to activate it. The activated enzyme produces $\mathrm{AMP}$ from ATP. This activation is turned off by hydrolysis of the bound GTP. The nucleotide, in turn, acts on its own target enzymes - the protein kinases. These enzymes consist of catalytic subunits which are inhibited by regulatory subunits. Binding of $\mathrm{cAMP}$ by the regulatory subunit releases this inhibition, which then allows the catalytic subunit to phosphorylate a variety of proteins. Some of the phosphorylated proteins can form either part of the transporters or their regulatory domains. This extremely complex system provides amplification at each step and affords the possibilities of fine tuning. In this sense it resembles the complex series of events that constitute the clotting cascade and serves to underscore Nature's penchant for repeated variations on a theme.

Calcium ions: Alterations in intracellular calcium ion concentration can serve to alter membrane transport processes. In most cells, the level of intracellular calcium is determined by three major mechanisms - the entry of calcium ions from the extracellular space into the cytosol across the plasma membrane; the extrusion of calcium ions from the cell by an energy-dependent process; and the release or sequestration of calcium ions by intracellular organelles such as the endoplasmic reticulum or mitochondria. Increases in intracellular calcium can be brought about by promotion of the inward movement of calcium ions through specific calcium ion channels, or by release of bound calcium. This latter effect can be achieved by alteration of the levels of other mediators such as cAMP or inositol phosphates. Thus acetylcholine acting on muscarinic receptors increases the turnover of phosphoinositides and the production of inositol 3,4,5-triphosphate, which in turn can release calcium ions from the endoplasmic reticulum. Increases in intracellular calcium decrease electrolyte absorption and promote anion secretion. Conversely, decreases in intracellular calcium can increase electrolyte absorption and decrease anion secretion. Changes in intracellular calcium can have complex effects on cyclic nucleotide processes and may act either in concert or opposition (15). 


\section{CONTRALUMINAL}

LUMINAL

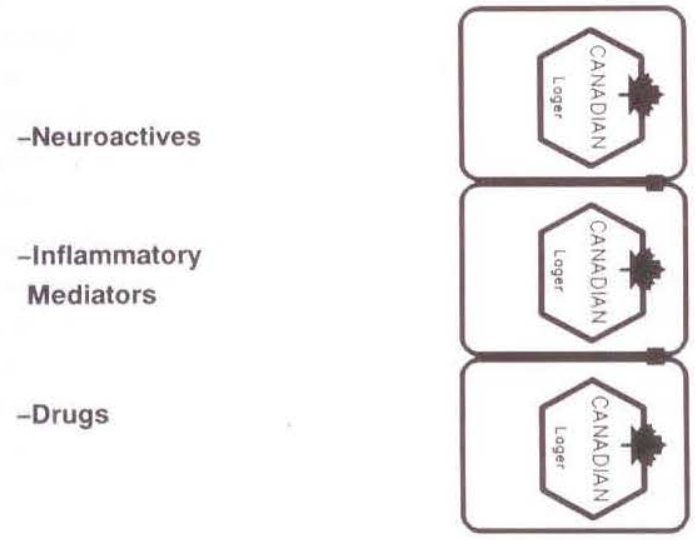

-Normal Flora

-Pathogens

-Drugs

-Bile Salts

Figure 5) The diverse factors that can modulate enterocyte function from the luminal and contraluminal sides

Phospholipids present in the plasma membranes of most cells can act as the source of intracellular messengers. Receptor occupation by specific hormones can lead to the hydrolysis of an inositol phospholipid in the membrane, generating two sets of messengers. One of these, inositol triphosphate (IP3), is released into the cytosol where it mobilizes calcium ions from internal stores. The other, diacylglycerol (DAG), remains in the plane of the membrane and activates protein kinase $\mathrm{C}$ which can phosphorylate effector proteins (16).

The numerous roles played by these second messengers have been elucidated in classical reductionist fashion by the isolation of individual elements for ease of analysis. It must be emphasized that the situation in vivo may be quite complex and not easy to predict.

The arguments to this stage can be summarized as follows. Epithelial cells are polarized and organized into sheets. The transport characteristics of the apical membranes are distinct from those of the basolateral membranes. The cells are organized into sheets to produce net movement of solutes and water across the entire sheet. In the intest ine, movement of solutes and water occur in both directions; the direction of net movement could be either from lumen to blood (net absorption) or from blood to lumen (net secretion) (5). Constipa- tion or diarrhea can be related to shifts in balance towards net absorption or net secretion.

Given that the epithelial cells exhibit a 'sidedness,' it can be anticipated that the transport properties can be modulated from either luminal or contraluminal side. Such modulations could shift the balance towards net $a b$ sorption or net secretion, and thus have consequences for the total functioning of the gut. Some factors that can modulate the transport properties of the gut are shown in Figure 5.

\section{CONTRALUMINAL FACTORS}

Neuroactive substances: This group of substances includes both neurotransmitters and enteroendocrine substances. The former are present in nerve endings and are released on neural stimulation, whereas the latter are present in paracrine or endocrine cells in the intestinal epithelium or lamina propria. In several instances, the same substances (vasoactive intestinal peptide and serotonin) are present in both locations.

The intestines are densely innervated. A special subset of the autonomic nervous system, the enteric nervous system appears to constitute virtually a 'little brain.' There are approximately $10^{8}$ neurons in the enteric nervous systems; as many as are in the spinal cord. The activity of this 'little brain' can be modulated by extrinsic projections from the central nervous system, allowing the 'big brain' to exercise overall integrative control (7). A large number of neurotransmitters have been identified. These include acetylcholine and catecholamines, as well as a list of peptides (vasoactive intestinal peptide, dynorphin, substance $\mathrm{P}$, galanin, somatostatin and neuropeptide Y). The physiological and pathophysiological implications of this vast number of neurotransmitters are only now being explored (6).

The messengers present in the enteroendocrine cells include, among others, motilin, neurotensin, secretin, vasoactive intestinal peptide and sero. tonin. The messengers discharged from these cells can function as true hormones, being carried to distant sites in the bloodstream, or can act in a paracrine fashion to modulate functions of adjacent cells. In instances where tumours of the enteroendocrine cells occur, the products can have profound effects on enterocytes. The classical example is that of 'watery diarrhea syndrome,' where vasoactive intestinal peptide appears to be the major culprit. Inflammatory mediators (6): Acute or chronic inflammation is associated with the production of a variety of mediators that include, among others, histamine, serotonin, kinins, arachidonic acid metabolites and lymphokines. These substances can alter enterocyte function directly by occupying receptors, or indirectly by altering the activity of enteric nerves. Alterations in the production of these mediators in diverse inflammatory states could have profound consequences for the absorptive and secretory functions of the intestine.

\section{LUMINAL FACTORS}

Intestinal microflora $(18,19)$ : Earlier, a comparison was made between the renal tubule and the gut. Although such comparisons are valid from a transport perspective, they are clearly inadequate when other factors are considered. While the contents of the renal tubule are bacteriologically sterile under normal conditions, the lumen of the gut is 
ABSORPTION

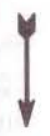

Neuroactives

SOMATOSTATIN

ENKEPHALINS

NOREPINEPHAINE

DOPAMINE

VASOPRESSIN

Steroids

CORTISOL

ALDOSTERONE

Drugs

LOPERAMIDE, CLONIDINE

BERBERINE

ORAL REHYDRATION SOLUTIONS

\section{SECRETION}

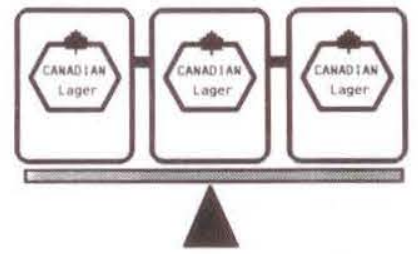

\section{l}

Neuroactives

VIP, SUBSTANCE P

ACETYL CHOLINE

5- HT

ADENOSINE

NEUROTENSIN

Inflammatory Mediators

HISTAMINE, KININS, 5-HT

ARACHIDONIC ACID METABOLITES

\section{Drugs}

LAXATIVES

Bacterial Toxins

Figure 6) The diverse factors that modulate enterocyte function and thus tilt the balance in favour of either net absorption or net secretion. VIP Vasoactive intestinal peptide; 5-HT Serotonin

a haven for bacteria. Thus, in comparison with the colon of a 'germ-free' animal, that of a 'normal' animal appears chronically inflamed. Studies of human gut flora are difficult because of the number and type of organisms present. Over 100 species and subspecies are found in the human gut. These include aerobes, facultative anaerobes and anaerobes. The numbers increase towards the distal segments, bacterial density increasing sharply in the colon where the average fecal bacterial count may be as high as $10^{9} / \mathrm{g}$.

The metabolic capacity of colonic flora is quite diverse and can be modulated significantly by variations in diet or drugs. This extensive capacity has both therapeutic and toxigenic potential.

Sulphasalazine is a drug that is widely used for the treatment of inflammatory bowel disease. The drug consists of two parts - sulphapyridine linked by an azobond to 5-aminosalicylate. On oral administration, the drug is transformed by azo-reductases of the gut flora to liberate the two moieties. The poorly absorbed 5-aminosalicylate remains in the gut to exercise its therapeutic effect while sulphapyridine is absorbed and excreted by the kidneys. Some of the variability in response to sulphasalazine could be linked to the varying amounts of the active moiety liberated due to altered metabolic capacity of the intestinal flora.

The toxigenic potential of intestinal flora is high. Reduction of azo compounds by gut flora often produces amines that are more toxic than the parent compound. This happens with food colourings such as Brown FK, Red 2G, Red 10B, Orange G and Orange RN. Amino acids can be metabolized by decarboxylation to produce pharmacologically active monoamines and diamines such as histamine from histidine, tryptamine from tryptophan, and tyramine from tyrosine. These compounds can evoke severe reactions. It is thus possible that patients who complain of allergies to certain foodstuffs are suffering the consequences of metabolites produced by their gut flora rather than true allergies in the immunological sense.

Pathogenic organisms (5): Pathogens that alter enterocyte function from the luminal side can do so either by invading and damaging the intestinal mucosa, by producing toxins that alter absorptive and secretory functions of the mucosa, or by a combination of both.

Invasive organisms that damage the mucosa include viruses (Norwalk, rotavirus), bacteria (Campylobacter jejuni,
Salmonella species, Shigella species, Yersinia enterocolitica, Escherichia coli, etc), protozoa (Giardia entamoeba) and a variety of helminths. Clearly, when the absorptive surface has been destroyed, the balance tilts in favour of net secretion, and in a number of instances this is further aggravated by crypt cell hyperplasia.

Toxin-producing bacteria include $E$ coli, Vibrio cholera, Clostridium difficile, Staphylococcus aureus and Shigella species. Two kinds of toxins are produced. The term 'enterotoxin' refers to toxins that cause fluid secretion without damaging the mucosal lining, whereas cytotoxins refer to those producing cell lysis and death. Cholera enterotoxin is the prototype of an enterotoxin, and shigatoxin produced by shigella dysentery is the prototype of a cytotoxin.

Choleratoxin consists of two subunits, A and B. The latter binds to specific receptors, gangliosides, on the luminal surface of the epithelial cell, and the A subunit is inserted into the cell. Within the cell, the A subunit prevents hydrolysis of the complex between the $\alpha$ subunit of the G-protein and GTP. This in turn has the effect of keeping adenylate cyclase in an irreversibly activated state, leading to a persistent elevation in the level of cAMP. The consequence of this persistent increase are twofold - inhibition of sodium and chloride ion absorption in the villus cell, and promotion of active anion secretion in the crypt cell. These changes result in an increase of solutes in the lumen of the gut with retention of water. The excess of fluid overwhelms the absorptive capacities of the colon, and diarrhea results. The $\mathrm{Na}^{+} /$glucose symport is unaffected, thus permitting the use of oral rehydration therapy. It is important to emphasize that this classical description may not be the whole picture, and there are suggestions that the enteric nerves and eicosanoids may be involved.

Bile salts, laxatives and drugs (4): Other luminal factors that can profoundly alter intestinal function include dietary constituents, endogenous secretions and a variety of drugs. Bile acids are endogenous secretions that are 
of considerable significance, as they are considered to be physiological laxatives. They appear to promote net fluid and electrolyte secretion either by altering mucosal permeability (making the junctions between cells leaky) or by promoting anion secretion. The latter effect can be achieved either by increasing the intracellular levels of calcium ions or CAMP, by stimulation of local enteric reflexes, or by release of prostaglandins. Four commonly used laxatives - bisacodyl, ricinoleic acid, phenolphthalein and senna anthraquinones - appear to stimulate the release of prostaglandins as well.

A large number of drugs can produce either diarrhea or constipation as a recognized side effect. Thus $40 \%$ of patients treated with the gold com-

ACKNOWLEDGEMENTS: I thank Todd Prior for his patience in preparing the figures, Mary Lambert for her ungrudging help in preparing this manuscript, and the Medical Research Council of Canada for support.

\section{REFERENCES}

1. Binder HJ, Sandle GJ. Electrolyte ab. sorption and secretion in the mammalian colon. In: Johnson LR, ed. Physiology of the Gastrointestinal Tract, 2nd edn. New York: Raven Press, 1987:1389-417.

2. Bridges RJ, Rummel W. Mechanistic basis of alterations in mucosal water and electrolyte transports. Clin Gastroenterol 1986;15:491-506.

3. Fedorak R, Field M. Antidiarrheal therapy. Dig Dis Sci 1987;2:195-205.

4. Ewe K. Intestinal transport in constipation and diarrhea. Pharmacology 1988;36(Suppl 1):73-84.

5. Taylor CE, Greenough WB. Control of diarrheal diseases. Annu Rev Public Health 1989;10:221-44.

6. Powell DW. Ion and water transport in pound auranofin for rheumatoid arthritis experience a variety of gastrointestinal side effects. These range from loose stools to frank diarrhea. The mechanisms responsible include both inhibition of absorption and activation of secretion. The enteric nerves appeared to be activated as well. In the case of auranofin, it appears that there is permeation of the drug from the luminal side (20).

It must be emphasized that a number of drugs affect enterocyte function from the contraluminal side. These include drugs given as antidiarrheals, such as loperamide or clonidine, as well as those given for other purposes that may have intestinal side effects (3). Figure 6 summarizes the diverse factors that can modulate enterocyte function and tilt

the intestine. In: Andreoli TE,

Hoffman JF, Fanestil DD, Schultz SG, eds. Physiology of Membrane Disorders. New York: Plenum Press, 1986:559-94.

7. Cooke HJ. Role of the 'little brain' in the gut in water and electrolyte homeostasis. FASEB J 1989;3:127-38.

8. Hubel KA. Neural control of intestinal electrolyte control. In: Davison JS, Shaffer EA, eds. Gastrointestinal and Hepatic Secretions: Mechanism and Control. Calgary: University of Calgary Press, 1988:175-80.

9. Turnberg LS. Pathophysiology of diarrhoea. In: Misciewicz JJ, Pounder RF, Venable CW, eds. Diseases of the Gut and Pancreas. Oxford, Boston: Blackwell Scientific Publishers, 1987:41-58.

10. Snyder J. Too many deaths from diarrhea? JAMA 1988;260:3329.

11. Ho MS, Glass RI, Pinsky PF, et al. Diarrheal deaths in American children. Are they preventable? JAMA 1988;260:3281-5.

12. Diamond JR. The epithelial junction: Bridge, gate and fence. Physiologist 1977;20:10-8.

13. Rodriguez-Boulan E, Nelson WJ. Morphogenesis of the polarised epithelial cell phenotype. Science the balance toward either net absorption or net secretion.

\section{CONCLUSION}

The objective of this article has been to provide a simple conceptual framework for the intestinal lining. Diamond's six-pack model emphasizes the crucial role of geometry in epithelial function. Placing the six-pack on a fulcrum serves to underscore the dynamic tension between secretion and absorption. Though admittedly simplistic, it is hoped that this framework will prove useful to busy clinicians as they attempt to comprehend the diverse influences that impinge on that marvellous lining, the malfunc. tion of which leads patients to their offices with embarrassing complaints.

1989;245:718-25.

14. Stewart CP, Turnberg LA.

A microelectrode study of responses to secretagogues by epithelial cells on villus and crypt of rat small intestine. Am J Physiol (Gastrointest Liver Physiol 20) 1989;257:G334-43.

15. Brown DR, Chandan R, Quito FL, Seybold VS. Receptor regulation of ion transport in the intestinal epithelium. Life Sci 1988;43:2193-201.

16. Brown AM, Birnbaumer L. Ion channels and $G$ proteins. Hosp Pract 1989;24:189-204.

17. Berridge MJ. Inositol triphosphate and diacylglycerol: Two interacting second messengers. Annu Rev Biochem 1987;56:159-93.

18. Goldman P. Biochemical pharmacology of the intestinal flora. Annu Rev Pharmacol Toxicol 1978;18:523-39.

19. Conning DM, Lansdown AB. Toxic hazards in food. London, Canberra: Croom Helm, 1983.

20. Rangachari PK, Kean WF. Gold and D-penicillamine and the gastrointestinal tract. In: Rooney PJ, ed. The Gut and Rheumatic Disease. Baillière's Clinical Rheumatology, Vol 3(2). London: Baillière Tindall, 1989:411-23. 


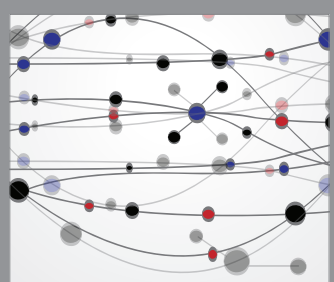

The Scientific World Journal
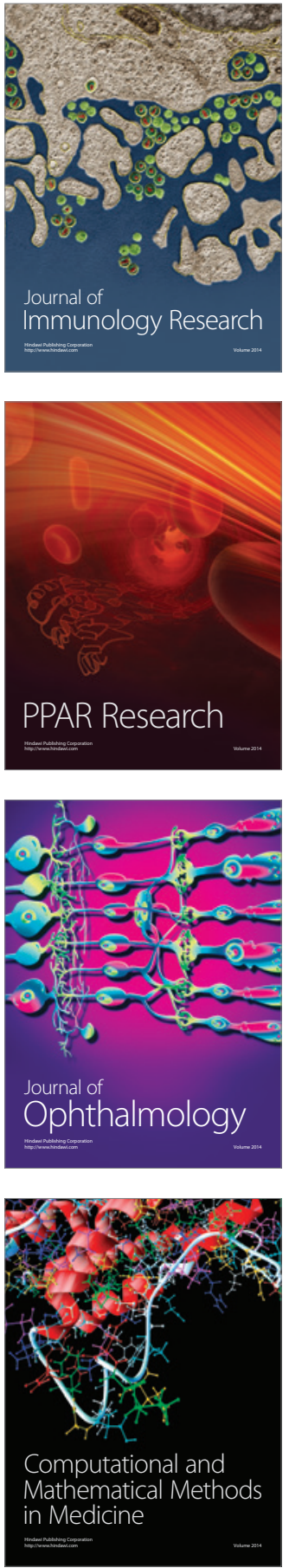

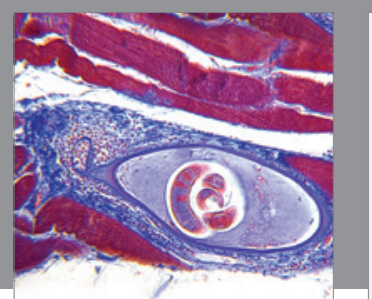

Gastroenterology Research and Practice

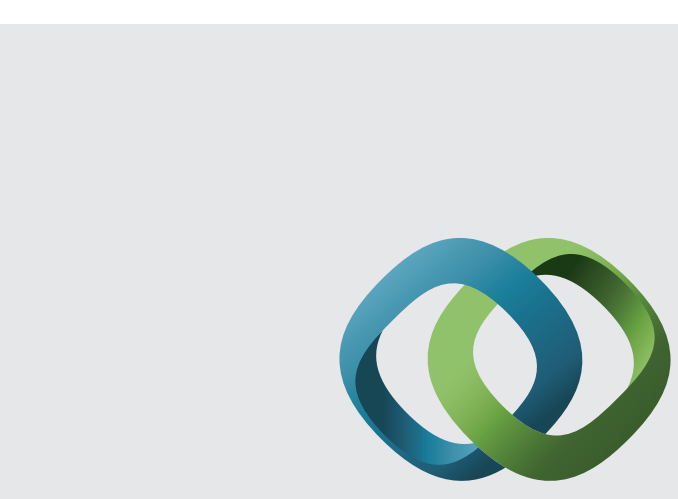

\section{Hindawi}

Submit your manuscripts at

http://www.hindawi.com
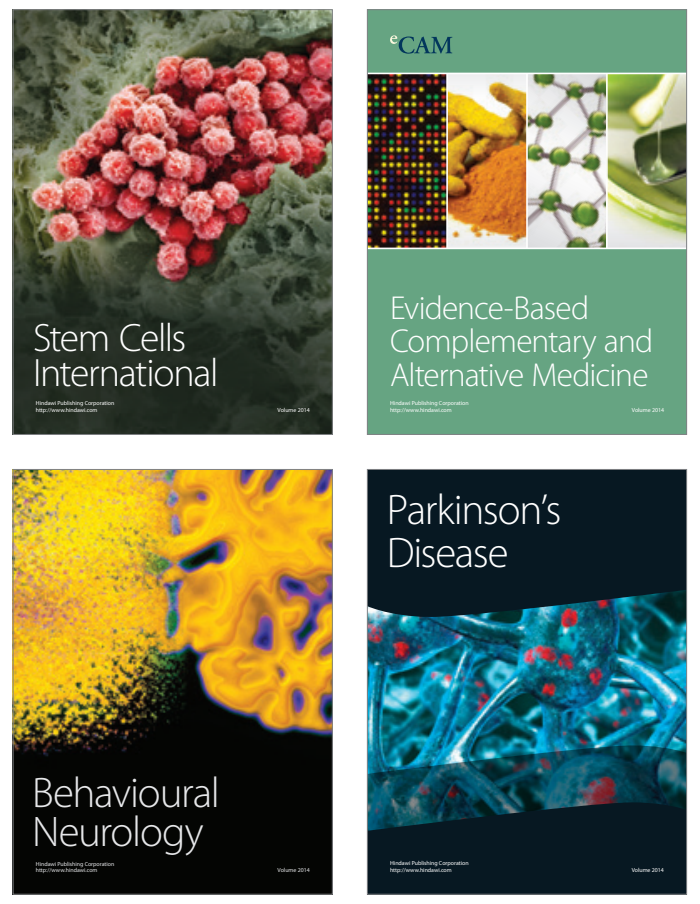
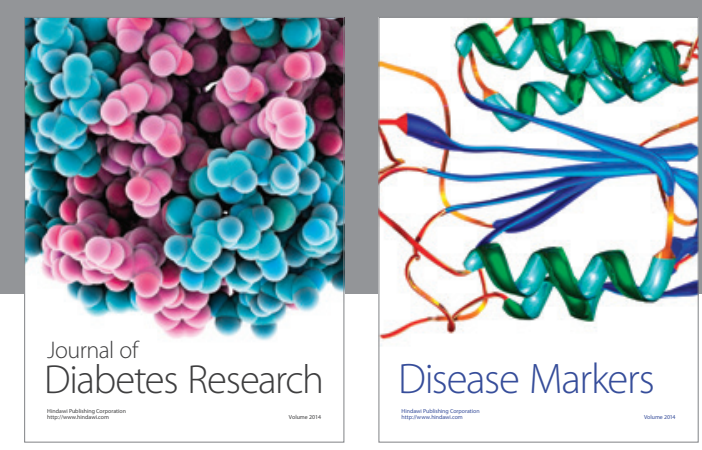

Disease Markers
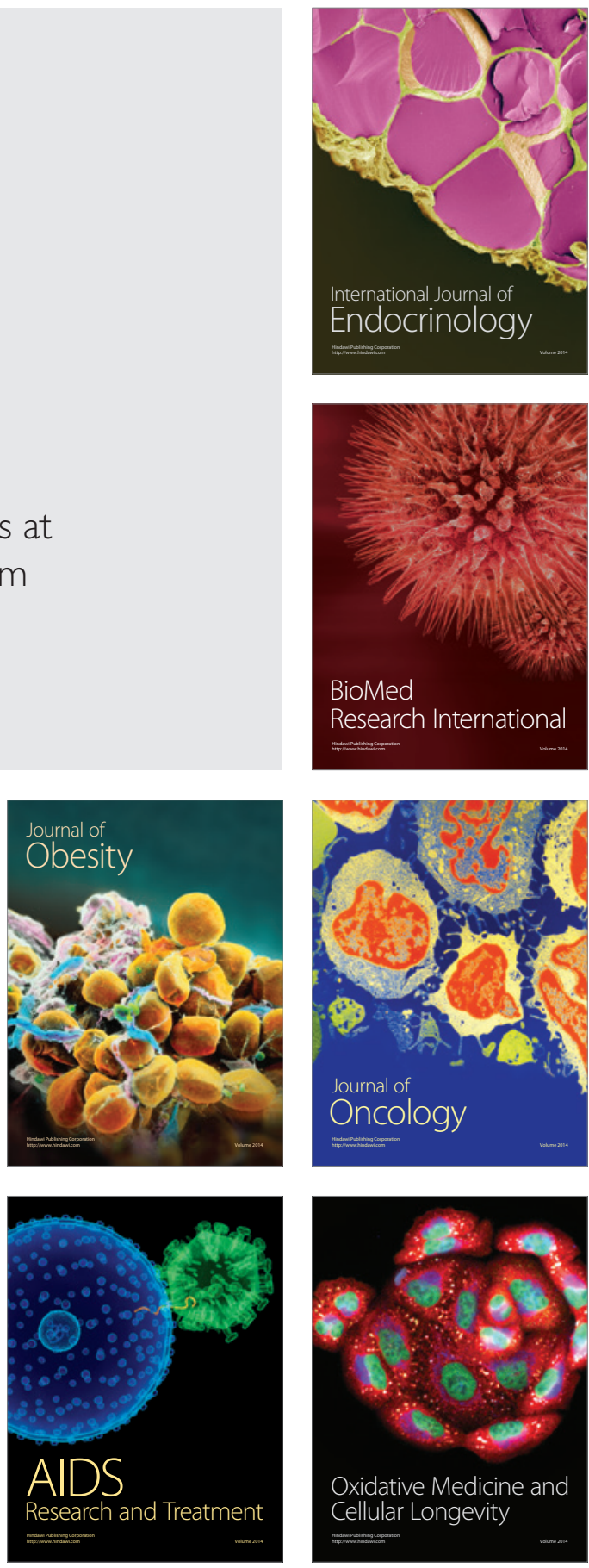